\title{
Review \\ The Role of the Universally Conserved ATPase YchF/Ola1 in Translation Regulation during Cellular Stress
}

\author{
Victoria Landwehr ${ }^{1}$, Martin Milanov ${ }^{1,2,3}$, Jiang Hong ${ }^{1,2,3}$ and Hans-Georg Koch 1,*(D) \\ 1 Institut für Biochemie und Molekularbiologie, ZBMZ, Fakultät für Medizin, Albert-Ludwigs-Universität \\ Freiburg, 79104 Freiburg, Germany; victoria.Landwehr@t-online.de (V.L.); \\ Martin.Milanov@biochemie.uni-freiburg.de (M.M.); hongj.jackie@gmail.com (J.H.) \\ 2 Fakultät für Biologie, Albert-Ludwigs-Universität Freiburg, 79104 Freiburg, Germany \\ 3 Spemann-Graduate School of Biology and Medicine, Albert-Ludwigs-Universität Freiburg, \\ 79104 Freiburg, Germany \\ * Correspondence: Hans-Georg.Koch@biochemie.uni-freiburg.de
}

check for updates

Citation: Landwehr, V.; Milanov, M.; Hong, J.; Koch, H.-G. The Role of the Universally Conserved ATPase YchF/Ola1 in Translation Regulation during Cellular Stress.

Microorganisms 2022, 10, 14.

https: / /doi.org/10.3390/

microorganisms10010014

Academic Editor: José Marques Andrade

Received: 27 November 2021

Accepted: 20 December 2021

Published: 23 December 2021

Publisher's Note: MDPI stays neutral with regard to jurisdictional claims in published maps and institutional affiliations.

Copyright: (c) 2021 by the authors. Licensee MDPI, Basel, Switzerland. This article is an open access article distributed under the terms and conditions of the Creative Commons Attribution (CC BY) license (https:/ / creativecommons.org/licenses/by/ $4.0 /)$.

\begin{abstract}
The ability to respond to metabolic or environmental changes is an essential feature in all cells and involves both transcriptional and translational regulators that adjust the metabolic activity to fluctuating conditions. While transcriptional regulation has been studied in detail, the important role of the ribosome as an additional player in regulating gene expression is only beginning to emerge. Ribosome-interacting proteins are central to this translational regulation and include universally conserved ribosome interacting proteins, such as the ATPase YchF (Ola1 in eukaryotes). In both eukaryotes and bacteria, the cellular concentrations of YchF/Ola1 determine the ability to cope with different stress conditions and are linked to several pathologies in humans. The available data indicate that $\mathrm{YchF} / \mathrm{Ola} 1$ regulates the stress response via controlling non-canonical translation initiation and via protein degradation. Although the molecular mechanisms appear to be different between bacteria and eukaryotes, increased non-canonical translation initiation is a common consequence of YchF/Ola1 regulated translational control in E. coli and H. sapiens. In this review, we summarize recent insights into the role of the universally conserved ATPase YchF/Ola1 in adapting translation to unfavourable conditions.
\end{abstract}

Keywords: YchF; Ola1; ribosomes; stress response; GTPases; ATPases; translation initiation; leaderless mRNA

\section{Introduction}

All cells, in particular unicellular organisms, are permanently challenged by rapid environmental changes and therefore depend on sophisticated mechanisms for adjusting their metabolic activity to external cues. In bacteria, a major hallmark of these adjustments are transcriptional regulators, such as two-component systems $[1,2]$ or various sigma factors [3] that rapidly adapt gene expression in response to, e.g., temperature shifts, $\mathrm{pH}$ shifts or nutrient limitation. In addition to these well-studied transcriptional responses, bacteria also adjust their metabolism by modifying the translational activity of the ribosome [4-6]. Examples are the ribosome modulation factor (RMF) and the hibernation-promoting factor (HPF), which are produced during the stationary phase in Escherichia coli [7-9]. Both proteins sequentially interact with $70 \mathrm{~S}$ ribosomes and convert them into translationally inactive dimeric $100 \mathrm{~S}$ ribosomes. This rapidly reversible inactivation of ribosomes is considered to prevent ribosomal damage while simultaneously reducing the production of damageprone translation products. Another example for translational regulation is the so-called stringent response, which is initiated during nutrient limitation, e.g., shortage of amino acids $[10,11]$. The presence of an uncharged tRNA in the A-site of the ribosome serves as a signal for recruiting the GTP-pyrophosphokinase RelA to the ribosome. Subsequently, RelA phosphorylates GTP to the hyper-phosphorylated guanine-nucleotides pppGpp or ppGpp, collectively called alarmones $[12,13]$. The gradual increase in these alarmones allosterically 
regulates the specificity of RNA-polymerase, leading to reduced synthesis of ribosomal RNA and ribosomal proteins. In addition, alarmones competitively inhibit GTPases, such as initiation factor 2 (IF2), which further attenuates translation during substrate limitation.

Ribosome inactivation by dimer formation as well as (p)ppGpp production are typical stress responses in bacteria and not found in eukaryotes, with the exception of bacteriaderived organelles, such as chloroplasts $[14,15]$. However, there are also universally conserved stress response proteins acting on the ribosome, such as the P-loop ATPase YchF (Ola1 in eukaryotes) [16,17]. Although YchF belongs to the translation-factor-related (TRAFAC) class of GTPases, it preferentially hydrolyses ATP rather than GTP $[18,19]$. Deletion or depletion of ychF/ola1 in E. coli, Oryza sativa or Homo sapiens is associated with increased stress resistance, suggesting a role of YchF/Ola1 as a negative regulator of stress response pathways [16,20-22]. YchF is furthermore considered as a constituent of the minimal translation machinery in bacteria [23]. In this review, we summarize recent developments that shed light on the molecular functions of YchF/Ola1 in regulating the response to unfavourable cellular and environmental conditions.

\section{Structure of YchF/Ola1 and Its Interaction with Ribosomes}

YchF/Ola1 is a highly conserved three-domain protein (Figure 1), sharing $45 \%$ sequence identity and $62 \%$ sequence similarity between human Ola1 and E. coli YchF (Figure 2). YchF/Ola1 contains four conserved G-motifs (G1-G4), which defines YchF/Ola1 as a member of the large group of P-loop NTPases $[16,17,24]$. The G1-G3 motifs are located in the $\mathrm{N}$-terminal G-domain, which also contains a conserved serine residue (S16 in E. coli) and a widely conserved cysteine residue (C35 in E. coli), important for phosphorylation [25] and dimerization [26], respectively (Figure 2).

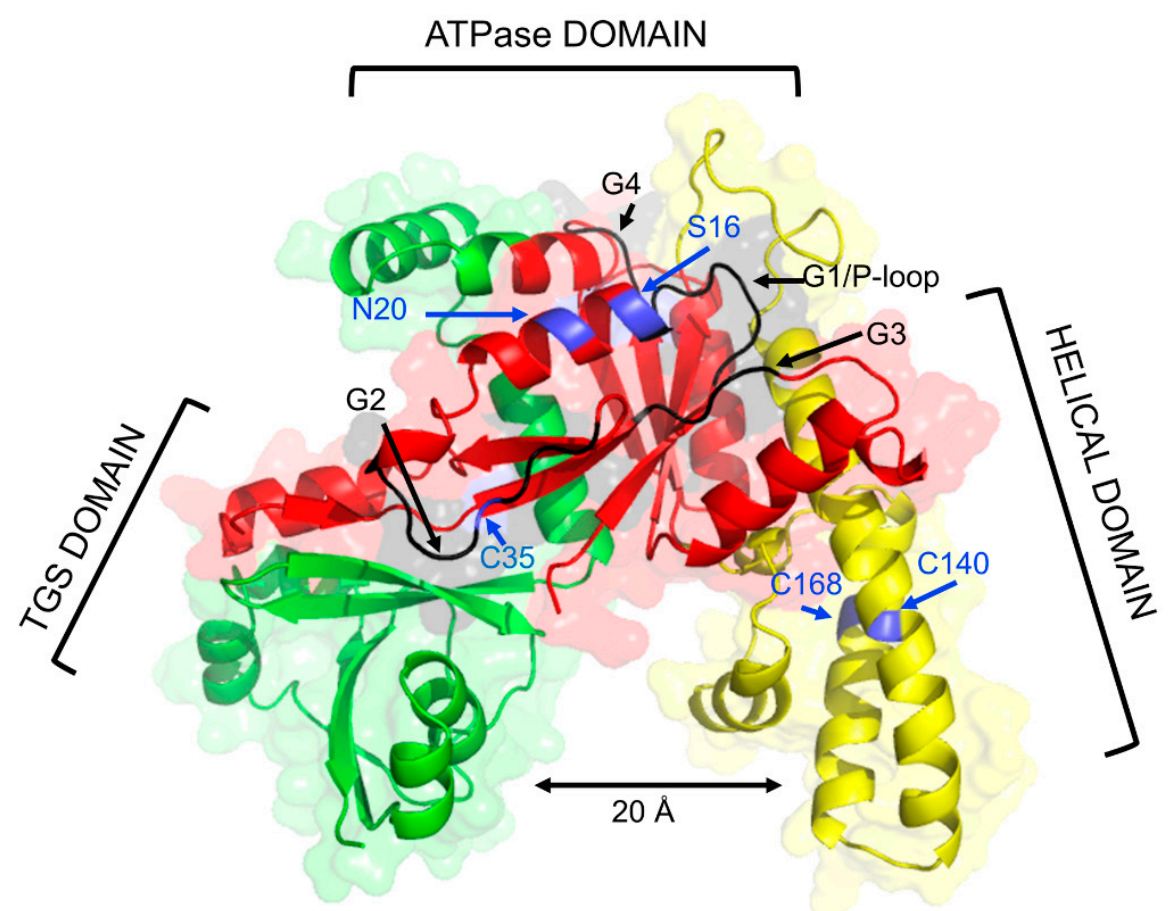

Figure 1. Structural model of E. coli YchF. The structure was retrieved from the Alphafold Protein Structure Databank (https://alphafold.ebi.ac.uk/, accessed on 27 November 2021). The ATPase domain is shown in red, the coiled-coil or helical domain in yellow and the TGS-domain in green. Indicated are the four G-motifs (G1-G4), which define and specify nucleotide binding, residue S16, which is phosphorylated, residue N20, which has been mainly used for in vivo site directed crosslinking and residue $\mathrm{C} 35$ that is involved in $\mathrm{YchF}$ dimerization. The helical domain contains two additional Cys residues in close proximity (C140 \& C168), which could act as a redox switch. 


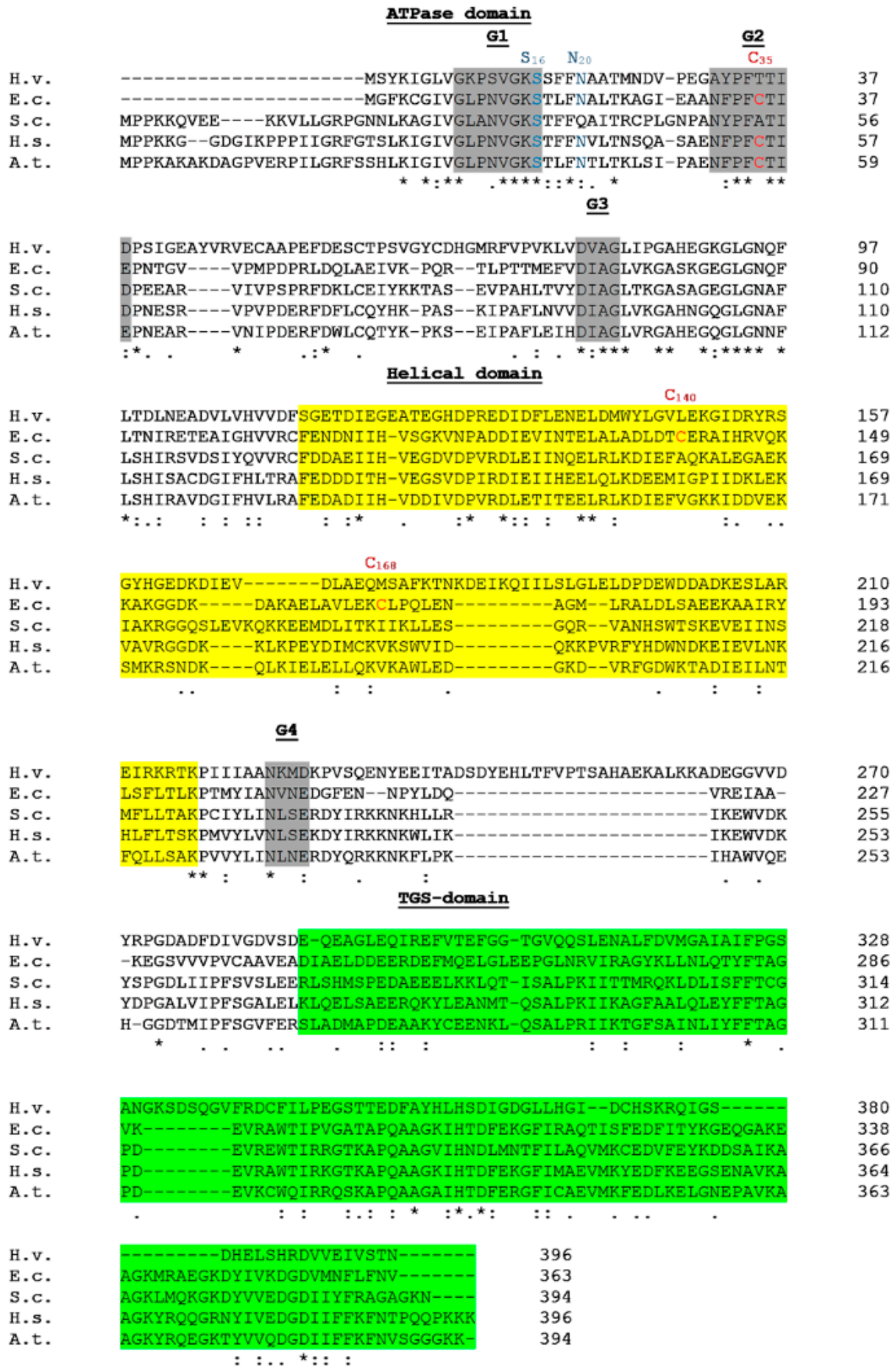

Figure 2. Sequence alignment of YchF/Ola1 from different species. Indicated are the three domains and the G1-G4-motifs, which define nucleotide binding and specificity. In addition, the conserved serine residue (S16 in E. coli), which was shown to be phosphorylated and the largely conserved cysteine residue (C35 in E. coli), which forms intermolecular disulphide-bridges, are indicated. YchF in $E$. coli and many other proteobacteria contains two additional closely spaced cysteine residues (C140 and C168 in E. coli), which could constitute a redox switch. H.v., Haloferax volcanii; E.c., Escherichia coli; S.c., Saccharomyces cerevisiae; H.s., Homo sapiens; A.t., Arabidopsis thaliana. Alignment was performed with the ClustalW multiple sequence alignment tool. $\left(^{*}\right)$ indicates positions which have a single, fully conserved residue; (:) indicates conservation between groups of strongly similar properties ( $>0.5$ in the Gonnet PAM 250 matrix) and (.) indicates conservation between groups of weakly similar properties ( $\leq 0.5$ in the Gonnet PAM 250 matrix). 
The G4 motif of YchF/Ola1 in most species differs from the canonical G4 motif in P-loop GTPases and is composed of NxxE instead of NKxD (Figure 2), which is likely responsible for the altered nucleotide specificity of YchF/Ola1 [19]. An exception is YchF of Haloferax volcanii, which contains the typical NKxD motif (Figure 2), but the nucleotide specificity of $H$. volcanii YchF has not been tested so far. The G-domain is followed by a helical domain (coiled-coil domain), which forms together with the C-terminal TGS (ThrRS, GTPase, SpoT)-domain, a large, approx. $20 \AA$ wide positively charged cleft, potentially favouring RNA interactions (Figure 1) [19,27]. The exact roles of the helical and the TGSdomains are unknown. In most proteobacteria, the helical domain of YchF contains two conserved additional cysteine residues (C140, C168 in E. coli), which are perfectly positioned for an intramolecular disulphide-bridge [26] (Figures 1 and 2). In E. coli, the helical domain was also shown to interact with thioredoxin 1 [26] and thus could act as a redox switch. The TGS-domain is present in many RNA-binding proteins, such as ObgE, ThreonyltRNA synthetase, (p)ppGpp synthase/hydrolase SpoT and the GTP-pyrophosphokinase RelA $[12,28,29]$. TGS-domains belong to the beta-grasp fold superfamily, which also include ubiquitin-like proteins [30], associated with post-translational modifications and proteolysis [31,32].

Within the TRAFAC class of GTPases, YchF/Ola1 belongs to the Obg-like protein family, which is associated with ribosome biogenesis and translational control $[16,17,33]$. In E. coli and other enterobacteria, $y c h F$ is encoded in one operon together with the gene for the essential peptidyl-tRNA hydrolase Pth [34], which catalyses the removal of peptides from peptidyl-tRNAs that have been prematurely released from the ribosome [35]. This also points to a ribosome-associated role of YchF. Thus, several studies have analysed ribosome binding of YchF/Ola1 and its potential effect on ribosome biogenesis in different organisms [36-42] (Table 1). A putative role in ribosome biogenesis has only been suggested for Arabidopsis thaliana AtYchF, based on the homology to known ribosome assembly factors, such as ObgE [40], but there is no experimental evidence for an involvement of $\mathrm{YchF} / \mathrm{Ola} 1 \mathrm{in}$ ribosome biogenesis so far. Studies in E. coli using a $\Delta y c h F$ strain or an $y c h F-$ overexpressing strain did not show any significant effect on the presence and quantities of the $30 \mathrm{~S}, 50 \mathrm{~S}, 70 \mathrm{~S}$ or polysome fractions $[43,44]$.

On the other hand, ribosome binding of YchF/Ola1 has been experimentally determined in E. coli [20,36,37,42], yeast [41,45], Trypanosoma [38], plants [40,46] and humans [39] (Table 1). Still, the specific binding site of YchF/Ola1 on the ribosome is unknown. Cofractionation studies indicate co-migration of YchF/Ola1 with the 30(40)S subunit, the 50(60)S subunit, 70(80)S ribosomes and polysomes [37-39,42]. Co-immune precipitation studies in Trypanosoma further indicate that YchF binds to the 60S ribosomal protein uL24 at the ribosomal tunnel exit and to the $40 \mathrm{~S}$ ribosomal protein eS7, which is implicated in rRNA processing and translational fidelity [38,47]. In vivo site-directed cross-linking studies confirmed contacts of $\mathrm{YchF}$ with both the $30 \mathrm{~S}$ and the $50 \mathrm{~S}$ ribosomal subunits in E. coli (Figure 3) [42]. The large majority of these contacts were found on the 30S subunit, e.g., uS5, uS8, uS11 and bS21, which are located at the interface between the 30S and 50S subunits, close to the mRNA entrance site (Figure 3) [42]. A similar contact of Ola1 to the 40S-60S interface is deduced from the observation that the over-production of Ola1 rescues the phenotypes associated with deletions of the ribosomal proteins uS17 and eS7 in yeast [45]. Both proteins are located at the mRNA corridor between the $40 \mathrm{~S}$ and $60 \mathrm{~S}$ subunits and are required for translational fidelity [48]. The cross-linking approach in E. coli also detected uL29 as a potential contact site for YchF [42]. Similar to uL24, uL29 is located at the ribosomal tunnel exit of the $50 \mathrm{~S}$ subunit [49], suggesting that YchF/Ola1 can interact with both subunits of the ribosome. The N-terminal ATPase domain of YchF appears to serve as a major contact site to the ribosome [42], which supports the observation that ribosome binding stimulates ATPase activity [36]. 


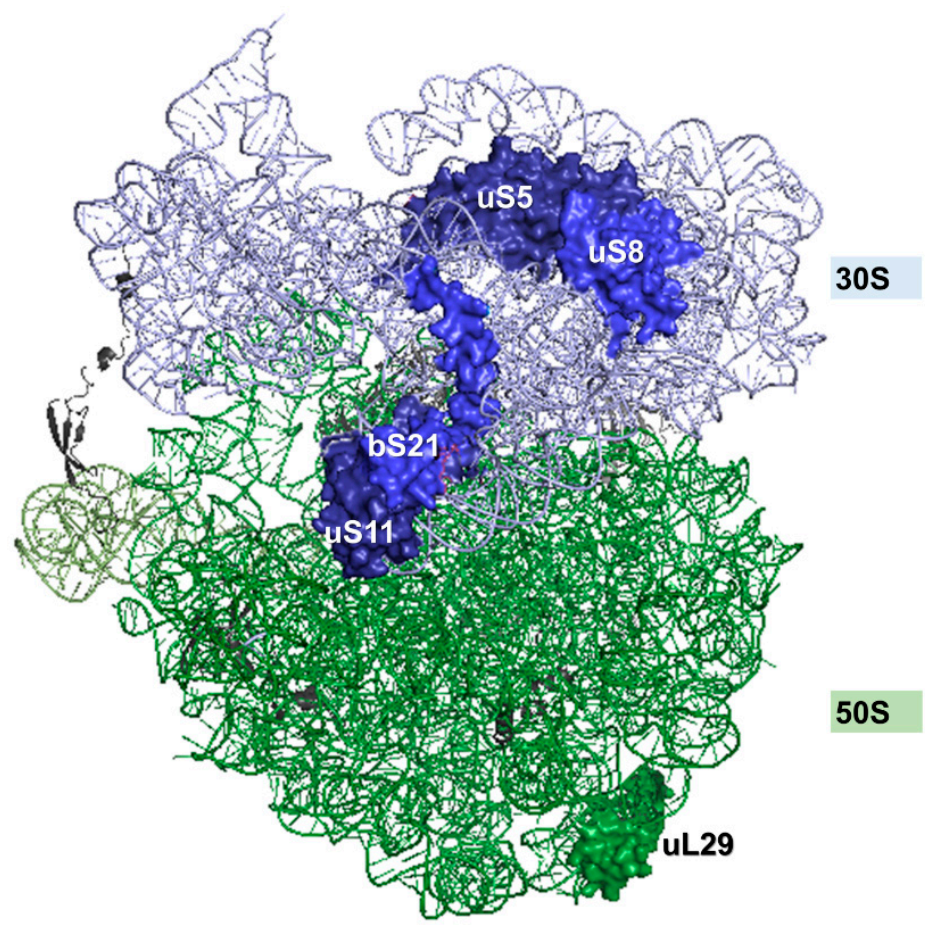

Figure 3. Contact sites for $\mathrm{YchF}$ on the E. coli $70 \mathrm{~S}$ ribosome. Contact sites were determined by site-directed in vivo cross-linking combined with mass spectrometry [42]. The $30 \mathrm{~S}$ ribosomal subunit is shown in light blue and ribosomal proteins that were identified as contact sites in dark blue. The $50 \mathrm{~S}$ ribosomal subunit is shown in light green and the ribosomal protein uL29, which was also found as contact site is indicated. The $70 \mathrm{~S}$ ribosome structure was retrieved from the protein data bank with the PDB code: $5 \mathrm{mdz}$ [44].

The available data so far do not support the presence of a single binding site for YchF on the ribosome. In E. coli, YchF is largely sub-stoichiometric to ribosomes [36,50] and only approx. $10 \%$ of all ribosomes can be in contact with YchF in vivo. Thus, most studies on ribosome binding were performed under YchF over-producing conditions, which likely influenced the YchF-ribosome interaction. This is supported by the observation that in E. coli wild type cells, YchF was exclusively found in the $30 \mathrm{~S}$ ribosomal fraction, while in YchF-over-producing cells it was found in the 30S, 50S, 70S and polysome fractions [42]. In accordance with the available functional data (see below) the $30 \mathrm{~S} / 40 \mathrm{~S}$ ribosomal subunit seems to be the preferred binding site for YchF/Ola1, while binding to the 50S/60S subunit is probably only transient $[36,38,39,42]$.

Table 1. Function of YchF/Ola1 in different species.

\begin{tabular}{|c|c|c|c|c|c|}
\hline Organism & $\begin{array}{l}\text { Ribosome } \\
\text { Binding }\end{array}$ & Translation & Proteolysis & $\begin{array}{c}\text { Cellular } \\
\text { Adaptation }\end{array}$ & References \\
\hline Escherichia coli & + & + & - & + & {$[20,36,42]$} \\
\hline Brucella melitensis & n.a. ${ }^{2}$ & n.a. & n.a. & + & {$[51,52]$} \\
\hline $\begin{array}{l}\text { Haemophilus } \\
\text { influenzeae }\end{array}$ & n.a. & n.a. & n.a. & + & {$[27]$} \\
\hline $\begin{array}{l}\text { Streptococcus } \\
\text { pneumonia }\end{array}$ & n.a. & n.a. & n.a. & + & [53] \\
\hline Vibrio vulnificus & n.a. & n.a. & n.a. & + & [54] \\
\hline $\begin{array}{c}\text { Saccharomyces } \\
\text { cerevisiae }\end{array}$ & + & + & + & + & {$[41,45,55]$} \\
\hline Arabidopsis thaliana & + & n.a. & n.a. & + & {$[22,40]$} \\
\hline Oriza sativa & + & n.a. & n.a. & + & {$[22,46,56]$} \\
\hline Trypanosoma cruzi & + & n.a. & + & n.a. & [38] \\
\hline Mus musculus & + & + & + & + & {$[39,57,58]$} \\
\hline Homo sapiens & + & + & + & + & {$[39,59,60]$} \\
\hline
\end{tabular}

${ }_{1}$ cellular adaptation includes stress response, metabolic alterations, virulence and other adaptation pathways that are influenced by YchF/Ola1; see text for details. ${ }^{2}$ n.a. $=$ not analysed $/$ no data available. 


\section{Cellular Roles of YchF/Ola1 in Stress Response}

Multiple studies have linked YchF/Ola1 to stress response pathways [20-22,26,39]. Intriguingly, the absence/depletion of YchF/Ola1 leads to a gain of function phenotype in some cases, i.e., the corresponding strains tolerate non-favourable conditions much better than wild type cells. This is shown for the $\Delta y c h F$ strain of $E$. coli, which is resistant against the replication inhibitor hydroxyurea and the translational inhibitor fusidic acid [42]. The reversal of these phenotypes is observed by providing just $y c h F$ in trans, demonstrating that the observed phenotypes are not caused by a reduced expression of the $p$ th gene, which forms a bicistronic transcript together with ychF $[20,26,42]$. Other examples for a stressrelated function of YchF/Ola1 is the increased resistance of Ola1-depleted cells against DNA-damaging agents $[61,62]$ or the increased salt sensitivity of plants, when YchF is over-produced [22,46,56]. Even though in some cases the absence of YchF/Ola1 is beneficial for cells encountering stress conditions, the $\Delta y c h F$ strain is rapidly outcompeted by wild type E. coli cells under non-stress conditions [42], pointing to an important role of YchF in cellular metabolism. This is also supported by the cold sensitivity of the $\Delta y c h F$ strain. The cold-sensitive phenotype is rescued by a plasmid-borne copy of wild type $y c h F$ but not by the ATPase-deficient mutant [20], suggesting that ATP hydrolysis is required for growth at sub-optimal temperatures. Cold sensitivity in bacteria is frequently associated with changes in membrane composition, e.g., alterations in lipid or protein composition [63,64]. Whether the absence of YchF has any impact on lipid or protein composition of the bacterial membrane is currently unknown, but the reduced iron uptake in $\Delta y c h F$ strains of Vibrio vulnificus and Brucella melitensis could support possible membrane alterations [51,54].

A common phenotype of ychF-deletion strains of E. coli and Ola1-depleted human cells is their increased resistance to reactive oxygen species (ROS), such as peroxides, and to thioldepleting agents, such as diamide $[20,21,26]$. In E. coli, ychF expression is downregulated when cells are exposed to $\mathrm{H}_{2} \mathrm{O}_{2}$ [20], indicating that lowering the $\mathrm{YchF}$ concentration is a physiological response against $\mathrm{ROS}$ accumulation. Accumulating $\mathrm{H}_{2} \mathrm{O}_{2}$ activates the oxidative stress-responsive transcription factor OxyR [65], which recognizes a specific binding motif within the $5^{\prime}$-UTR of $y c h F$ and prevents transcription initiation [20]. The transcriptional downregulation of $y c h F$ in $E$. coli is likely important during long-term ROS exposure [42], e.g., when cells transition from early exponential phase to late exponential and stationary phase, which is accompanied by increased ROS production [66]. E. coli YchF is also a substrate of the AAA-protease Lon [67], which is required for cellular homeostasis and for stress-induced developmental changes [68]. Thus, Lon-dependent proteolysis of YchF during stress conditions could additionally contribute to the decline of the YchF levels.

E. coli YchF co-purifies with catalases and many antioxidant proteins, including thioredoxin or glutaredoxin, suggesting that $\mathrm{YchF}$ could act as a direct inhibitor of antioxidant enzymes $[20,26]$. This is supported by a reduction in catalase activity when YchF is overproduced [20]. However, $\mathrm{YchF}$ does not inhibit the catalase activity of KatG in vitro [42], indicating that the reduced catalase activity is likely an indirect effect. On the other hand, the interaction of YchF with thioredoxin was shown to be required for dissociating the YchF dimer, which is formed by ROS-induced oxidation of the conserved Cys35-residue and intermolecular disulphide-bridge formation [26]. Within the YchF dimer, the ATP binding site is covered and hence dimerization prevents ATP hydrolysis [26]. The increased ATPase activity of YchF in the presence of ribosomes [36] thus indicates that monomeric YchF interacts with the ribosome. Cys35 is conserved in many species (Figure 2), suggesting that inactivation via ROS-induced disulphide-bridge formation is not limited to E. coli $[26,41]$. Overproduction of YchF increases ROS sensitivity, but this is not observed when the ATPbinding site in YchF is mutated, showing that ATP hydrolysis by the YchF monomer is important for regulating the oxidative stress response [20].

In bacteria and humans, reduced $\mathrm{YchF} / \mathrm{Ola1}$ levels increase the resistance against ROS and DNA-damaging agents, suggesting a role of $\mathrm{YchF} / \mathrm{Ola1}$ as negative regulator of these stress-response pathways. In contrast, Ola1 acts as positive regulator of the heat-shock response in humans and yeast $[41,69]$. Upon depletion of Ola1 in human cell lines, the levels 
of the heat-shock protein 70 (Hsp70) decrease, leading to increased temperature-induced cell death [69]. Ola1 was shown to bind to the C-terminus of Hsp70, thereby preventing its ubiquitination and proteasomal degradation [69]. The enhanced ubiquitination and degradation of Hsp70 in the absence of Ola1, but not of other heat-shock proteins [69], is likely responsible for the temperature sensitivity of Ola1-depleted human cells. A potential link between temperature sensitivity and peroxide resistance is provided by the increased degradation of the $\mathrm{H}_{2} \mathrm{O}_{2}$-generating enzyme superoxide dismutase when $\mathrm{Hsp} 70$ levels are reduced in the absence of Ola1 [59]. Due to the reduced intracellular $\mathrm{H}_{2} \mathrm{O}_{2}$ production, cells are potentially more resistant towards externally added $\mathrm{H}_{2} \mathrm{O}_{2}$.

Enhanced ubiquitination is also observed in $\Delta$ ola1 cells of yeast. Here, the absence of Ola1 increased the ubiquitination of heat-shock induced protein aggregates [41], and caused an up-regulation of heat-protective proteins, such as Hsp12, Hsp42 and the Vtc complex [41], which is involved in the synthesis of the chemical chaperone polyphosphate [70,71]. Yeast Ola1 was shown to assemble into heat-induced stress granules [72] and to be released from these granules upon stress relief [41]. In the absence of Ola1, recovery from heat stress is delayed because translation initiation is reduced [41] and it was suggested that Ola1 could serve as an early heat-shock responder that regulates proteostasis for preventing damage or misfolding of proteins [41]. A putative role of Ola1 in regulating ubiquitindependent protein degradation is supported by the observed interaction of Ola1/YchF with subunits of the proteasome $[38,41,55]$. The C-terminal TGS-domain of Ola1/YchF is a potential candidate for the interaction with the proteasome, due to its structural similarity to ubiquitin-like proteins [30].

The importance of well-balanced Ola1-levels is further highlighted by the observation that Ola1 is up-regulated in various human tumours, such as colorectal carcinoma and ovarian and lung cancer [61]. Clinical progression and prognosis of these tumours is influenced by the cellular Ola1 concentrations [57]. Tumour formation is at least partially linked to changes in Ser/Thr phosphorylation of some cancer-related proteins upon increased Ola1-levels. This includes glycogen synthase kinase-3 (GSK-3) [73], focal adhesion kinases (FAKs) [74], peptidyl-prolyl isomerase Pin1 [73,75] and eukaryotic initiation factor 2 (eIF2) [39]. Involvement of Ola1 in breast and ovarian cancer is likely connected to its interaction with a protein complex consisting of BRCA1 (breast cancer associated gene 1), BARD1 (BRCA1-associated Ring domain protein) and $\gamma$-tubulin [60,76]. This complex is associated with the centrosome and important for chromosome stability [77-79]. The BRCA1-BARD1 complex acts as a Ring-type E3 ubiquitin ligase, catalysing the ubiquitination of multiple substrate proteins [80]. The ubiquitin-like C-terminal TGS-domain of Ola1 is required for the interaction with the N-terminal domains of BRCA1 and BARD1 [60,78], which supports the functional importance of the TGS-domain in Ola1/YchF.

\section{The Role of YchF/Ola1 in Translation}

The available data support the primary role of YchF/Ola1 in regulating the proteostasis network when cells encounter stress conditions [81,82]. This includes translational regulation at the level of translation initiation $[39,41,42,58]$ and regulation of protein degradation $[59,69,73]$. Observations such as decreased cell migration, increased cell matrix adhesion [57,62] and reduced cell cycle progression [58] in the absence of Ola1 are likely either directly or indirectly linked to its role in proteostasis regulation.

Translation is primarily controlled at the energy-consuming initiation step, which is significantly different between eukaryotes and bacteria [83-85]. In eukaryotes, initiation starts with the formation of a ternary complex, consisting of eIF2-GTP, and the aminoacylated tRNAi ${ }^{\text {Met }}$ (eIF2-GTP-Met-tRNAi ${ }^{\text {Met, }}$ Figure $\left.4 \mathrm{~A}\right)$. In conjunction with the $40 \mathrm{~S}$ ribosomal subunit and additional initiation factors (eIF1, eIF2A, eIF3 and eIF5) the ternary complex forms a $43 \mathrm{~S}$ pre-initiation complex, which binds the activated mRNA. mRNA activation involves specific recognition of the m7G-Cap structure at the 5'end of the mRNA by the eIF4F complex. The resulting $48 \mathrm{~S}$ complex then scans the mRNA for identifying the start codon. Once the Met-tRNAi ${ }^{\text {Met }}$ has recognized the AUG start codon, eIF2 and other 
initiation factors are released, enabling 605 subunit binding, resulting in the elongation competent $80 \mathrm{~S}$ ribosome $[86,87]$. This Cap-dependent initiation is primarily regulated at the level of ternary complex formation via inactivation of eIF2 [88].

A

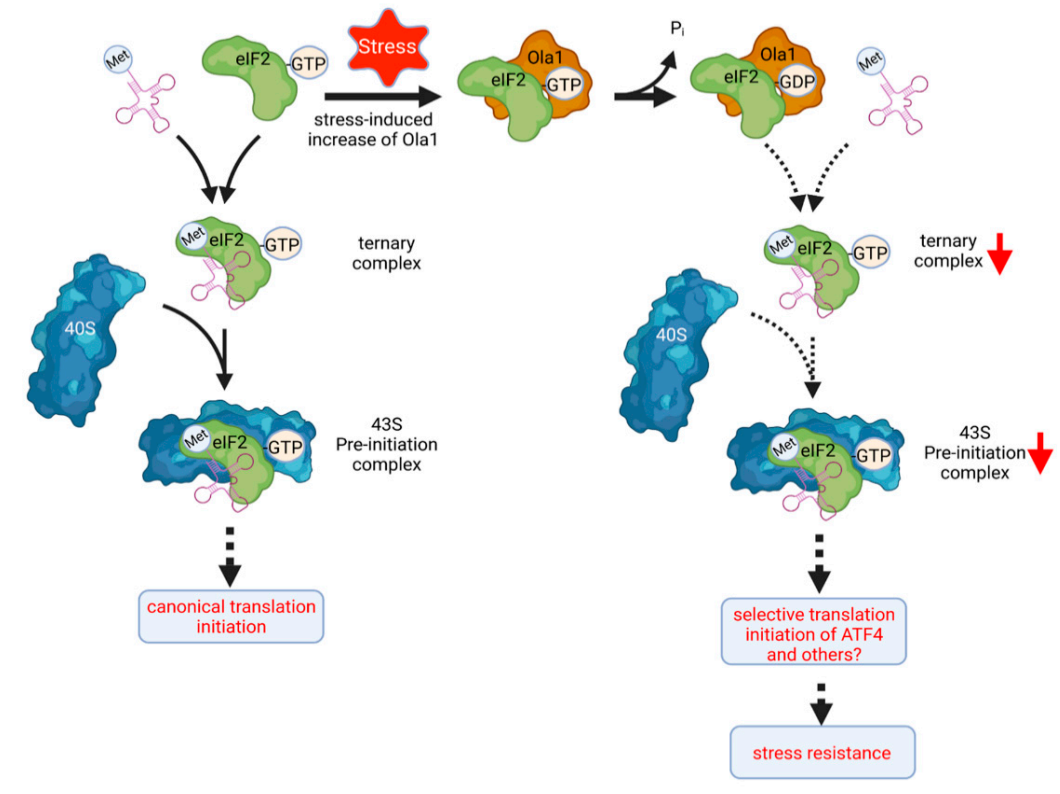

B

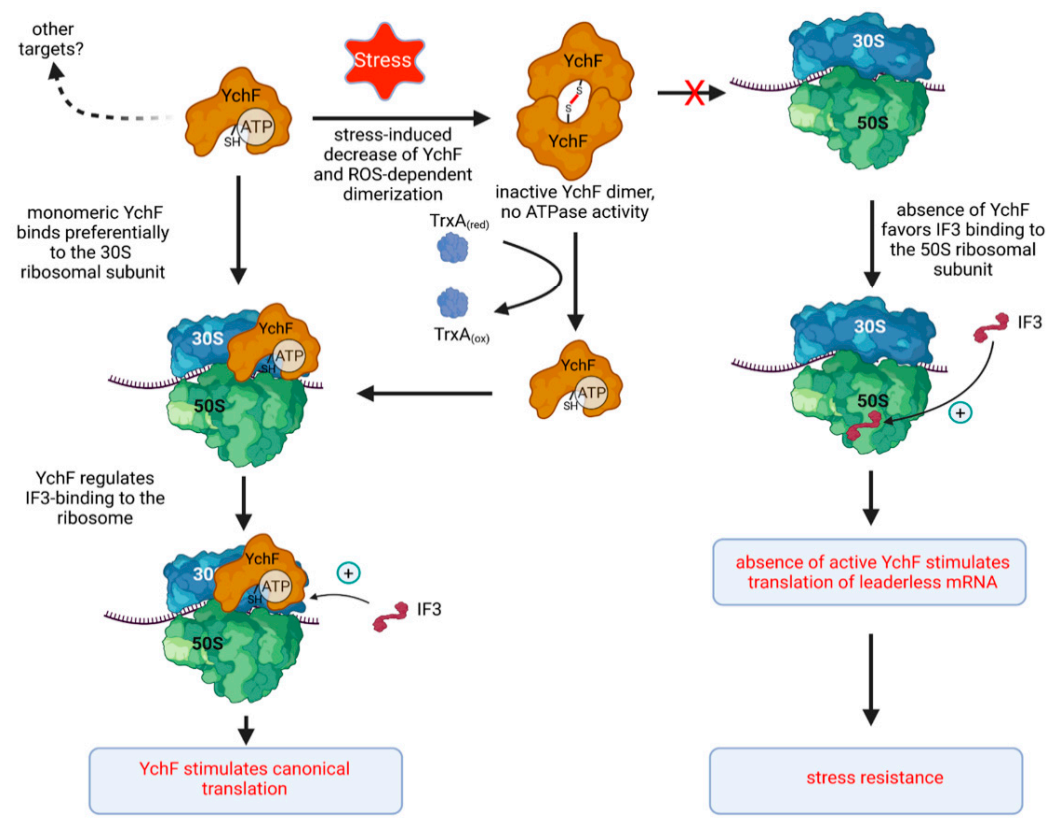

Figure 4. Model of translational regulation by Ola1/YchF. (A) In eukaryotes, Ola1 binds to eIF2 and stabilizes eIF2 in its GDP-bound state, which would subsequently reduce the formation of the ternary complex. As a consequence, alternative translation initiation mechanisms are favoured, leading to selective synthesis of stress-response proteins. (B) In prokaryotes, such as E. coli, YchF binds preferentially to the $30 \mathrm{~S}$ ribosomal subunit and regulates IF3-binding to the 30S subunit, which favours canonical translation initiation. Upon stress conditions, ychF expression is reduced and the ATPase activity of YchF is further inhibited by dimerization. The absence of active YchF possibly favours IF3 binding to the 50S subunit and stimulates leaderless mRNA translation. Note that YchF was also found in contact with the $50 \mathrm{~S}$ ribosomal subunit; this interaction is likely only transient and not depicted here, although it might be involved in regulating IF3 binding to the ribosome. TrxA corresponds to thioredoxin A, which was shown to dissociate the inactive YchF dimer into active YchF monomers [26]. See text for further details. 
Ola1 was shown to prevent ternary complex formation via binding to eIF2 [39], which would subsequently reduce protein synthesis (Figure 4A). Reduced formation of the ternary complex is a well-studied consequence of the activated integrated stress response (ISR) [89]. Activation of multiple kinases by the ISR leads to stress-induced inhibition of eIF2 via phosphorylation [86]. Ola1 is suggested to provide an alternative mechanism for reducing ternary complex formation by stabilizing the eIF2-GDP complex (Figure 4A), which would prevent further initiation events $[39,86]$. Although Cap-dependent translation is common under non-stress conditions, eukaryotic cells also engage Cap-independent translation mechanisms when they are exposed to stress [86,90,91]. One example for a Capindependent translation mechanism is the translation of the cAMP-dependent transcription factor ATF4, which is produced by a translation re-initiation mechanism in response to eIF2 phosphorylation $[90,92,93]$. Stimulated ATF4 production as a consequence of reduced ternary complex formation in the presence of Ola1 would then promote transcription of genes linked to oxidative stress, ER stress or nutrient limitation [94-96].

Thus, the available data suggest that upon stress conditions, increased Ola1-levels attenuate canonical translation initiation, while simultaneously favouring alternative translation initiation mechanisms, which stimulates cell survival under stress conditions (Figure 4A). This assumption is further supported by the observation that Ola1 did not inhibit the Cap-independent translation of viral proteins [39]. Translation of viral proteins is often initiated by mRNA elements called internal ribosome binding sites (IRES) [97], but IRES-based initiation is also frequently used for translating stress response proteins [98].

Translation initiation in bacteria deviates from initiation in eukaryotes and starts with the formation of an instable 30S pre-initiation complex. This complex contains the initiation factors (IF) IF1, IF2 and IF3, the fMet-tRNA ${ }^{\text {fMet }}$ and the mRNA, which is bound via its Shine-Dalgarno sequence to the anti-Shine-Dalgarno sequence within the 16S rRNA of the $30 S$ subunit $[85,99]$. The recognition of the AUG start codon by the fMet-tRNA ${ }^{\mathrm{fMet}}$ induces a conformational change that converts the $30 \mathrm{~S}$ pre-initiation complex into the $30 \mathrm{~S}$ initiation complex. Due to the conformational change, IF3 is destabilized and dissociates, allowing the recruitment of the 50S subunit and transition of the $30 \mathrm{~S}$ initiation complex to the $70 \mathrm{~S}$ initiation complex [100]. Dissociation of IF3 also weakens ribosome binding of IF1 and IF2, which dissociate during transition to the 70S initiation complex [85].

Similar to eukaryotes, bacteria engage alternative translation initiation mechanisms, and they are particularly important for those mRNAs that lack the Shine-Dalgarno sequence. The occurrence of these leaderless mRNAs (lmRNAs) is highly variable between species [101,102]. They are highly abundant in Deinococcus deserti (47\% of all mRNAs) and their translation is linked to the extreme stress resistance of this species [103]. 1mRNAs are also frequently observed in Mycobacterium spec. (33\% in M. avium) and expressed when cells encounter stress conditions [104-106]. In the halophilic archaeon Haloferax volcanii about $72 \%$ of all mRNAs are leaderless [107-109]. In proteobacteria, such as E. coli, the percentage of naturally occurring lmRNAs is rather low $(0.7 \%$ in E. coli BW25113) [101,110], but they can be generated by post-transcriptional processing of canonical mRNAs, e.g., by the ribonuclease MazF [111,112]. MazF constitutes the toxin of the MazEF toxin-antitoxin system [113,114]. Upon stress conditions, the labile anti-toxin MazE is proteolized and MazF is released for mRNA degradation $[5,113,115]$. Although MazF predominantly degrades mRNAs completely [116,117], it can also generate lmRNAs by cleaving off the Shine-Dalgarno sequence [111]. Among the predicted MazF targets are many mRNAs encoding for stress response proteins [112], which supports the idea that selective ImRNA translation is an important cornerstone of stress adaptation $[5,118]$.

Due to the absence of the Shine-Dalgarno sequence, the AUG initiation codon at the very $5^{\prime}$-end of the mRNA serves as a major signal for ribosome binding to these lmRNAs. However, in some bacterial species, including Bacteroidetes and Cyanobacteria, mRNAs contain a 5'-leader sequence without clearly recognizable Shine-Dalgarno motifs and their initiation is at least partially determined by the RNA structure around the initiation codon [102,119-121]. Most studies indicate that translation of mRNAs starting 
with the AUG start codon is initiated on 70S ribosomes in bacteria [101]. This is deduced from the observation that $70 \mathrm{~S}$ ribosomes bind ImRNAs with higher affinity than $30 \mathrm{~S}$ subunits [122] and that the stability of the 70S initiation complexes increased in the presence of lmRNA [123]. Translation of canonical mRNAs, but not that of lmRNAs, is inhibited by chemical cross-linking or by inactivation of ribosome recycling factors, which prevent dissociation of the $70 \mathrm{~S}$ ribosome [124]. This further supports the hypothesis that translation of $\operatorname{lmRNAs}$ is initiated on $70 \mathrm{~S}$ ribosomes.

Absence of YchF promotes translation of lmRNAs and reduces the translation of canonical mRNAs [42]. This is in line with reduced global protein synthesis of the $\Delta y c h F$ strain and the observation that $\Delta y c h F$ cells are outcompeted by wild type cells under nonstress conditions [42]. It was recently shown that IF3 transiently occupies a second binding site on the $50 \mathrm{~S}$ ribosomal subunit, which might be important for the translation initiation of lmRNAs [125]. IF3 and YchF occupy overlapping binding sites on the $30 \mathrm{~S}$ subunit $[42,126]$ and both also interact with the 50S subunit [42,125]. A direct contact between YchF and IF3 was furthermore demonstrated by cross-linking in vivo [42]. Thus, one attractive model is that YchF controls ImRNA translation by regulating IF3 binding to either the 30S or $50 \mathrm{~S}$ ribosomal subunit (Figure 4B). Under normal growth conditions, YchF supports IF3 binding to the $30 \mathrm{~S}$ subunit and thus favours canonical translation. When cells enter the stationary phase or encounter stress conditions, the YchF levels drop [42], while IF3 levels increase [127]. This enhances the interaction of IF3 with the 50S subunit and promotes ImRNA translation. This model is in line with recent data showing enhanced lmRNA translation under oxidative stress conditions [128], which are associated with reduced YchF levels [20].

In essence, a decrease in YchF and an increase in IF3 during the stationary phase or stress conditions would prepare the translation machinery for the increased lmRNAs accumulation that occurs due to increased MazF-dependent cleavage of the Shine-Dalgarno sequence under these conditions [111,112] (Figure 4B). Increased lmRNA translation in the absence of YchF possibly also explains the cold-sensitive phenotype of the E. coli $\Delta y c h F$ strain [20]. During cold shock, IF2 levels increase and IF2 accumulation stimulates lmRNA translation at the expense of canonical translation $[63,127]$. Further stimulation of lmRNA translation when YchF is absent, potentially reduces canonical translation to a level that impairs cell viability at low temperatures.

\section{Summary and Outlook}

The available data for human Ola1 and E. coli YchF support the hypothesis that Ola1/YchF regulates the proteostasis network by adjusting canonical and non-canonical translation initiation mechanisms in response to metabolic changes and stress conditions (Figure 4). The stress-induced decrease in YchF in E. coli and the stress-induced increase in Ola1 in humans favours in both cases an enhanced non-canonical translation initiation of mRNAs encoding for stress-response proteins and thus promote stress resistance. The differences in their mode of action likely reflects the differences in translation initiation between bacteria and eukaryotes $[87,99]$. So far, there are no data addressing the function of YchF in archaea, but such studies would be particularly revealing because lmRNAs are rather frequent in archaea and their translation initiation mechanism differs from the mechanisms described in eukaryotes and bacteria [109].

The potential role of YchF/Ola1 in proteolysis is less defined but supported by the observed interaction of Ola1 with subunits of the proteasome and by increased degradation of Hsp70 in the absence of Ola1 [38,41,69]. In bacteria, strong evidence for a role of $\mathrm{YchF}$ in proteolysis is still missing and requires further analysis. However, it is also important to note that the cellular concentration of YchF in bacteria is much lower than the Ola1 concentration in eukaryotes $[36,129]$. Thus, it is possible that the strictly ribosomeassociated function of YchF in bacteria evolved into a more general regulatory function of Ola1 in eukaryotes. This would also explain the multiple Ola1-related phenotypes that have been observed in human cells $[16,39,57,60,69,74]$. 
The exact function of ATP hydrolysis by YchF/Ola1 and the role of its post-translational modifications, such as phosphorylation of the conserved serine residue (Ser16 in E. coli), are also still unknown. ATP hydrolysis is clearly linked to its ribosome binding and to stress response $[20,26]$, but the consequences still need to be analysed in detail. Furthermore, it is unknown why Ola1/YchF have evolved into ATP-hydrolysing enzymes despite having their evolutionary origin within the GTPase family $[16,17]$. E. coli YchF and human Ola1 preferentially hydrolyse ATP over GTP [19,20], although GTP hydrolysis by human Ola1 has also been reported [39]. Hydrolysis of both ATP and GTP has also been shown for the YchF homologue in rice [22,56]. Using preferentially ATP rather than GTP is possibly explained by the increase in the cellular ATP levels during stress conditions, due to the inhibition of metabolic processes [130]. ATP accumulation potentially also increases the levels of the alarmone (p)ppApp [12,131], which acts similar to (p)ppGpp as a stress-signalling nucleotide, but with different regulatory effects [132]. Competitive inhibition of YchF by increasing (p)ppApp levels could help to fine-tune stress-response pathways. Finally, since GTP is highly sensitive to oxidation [133], using the less sensitive ATP might also be important for adjusting translation during oxidative stress conditions.

Despite the high sequence conservation, studies on YchF/Ola1 in different species failed to reveal a comprehensive functional model up to now. Nevertheless, recent data in E. coli and humans support a role in the regulation of non-canonical translation initiation, which can serve as a basis for future studies. Considering the documented connection between Ola1 levels and cancer, these studies will be particularly important for developing Ola1 as a potential therapeutic target.

Author Contributions: All authors were involved in writing and finalizing the manuscript. All authors have read and agreed to the published version of the manuscript. Figures were created with BioRender.com.

Funding: This work was supported by grants from the Deutsche Forschungsgemeinschaft (DFG) to H.G.-K. (DFG grants KO2184/8; KO2184/9 (SPP2002); and SFB1381, Project-ID 403222702), and by the Else-Kröner Fresenius Stiftung/ Motivate Program of the University Freiburg Medical School to V.L.

Institutional Review Board Statement: Not applicable.

Informed Consent Statement: Not applicable.

Data Availability Statement: Not applicable.

Conflicts of Interest: The authors declare no conflict of interest. The funders had no role in the design of the study; in the collection, analyses, or interpretation of data; in the writing of the manuscript, or in the decision to publish the results.

\section{References}

1. De Nadal, E.; Ammerer, G.; Posas, F. Controlling gene expression in response to stress. Nat. Rev. Genet. 2011, 12, 833-845. [CrossRef]

2. Ishii, E.; Eguchi, Y. Diversity in Sensing and Signaling of Bacterial Sensor Histidine Kinases. Biomolecules 2021, 11, 1524. [CrossRef]

3. Gottesman, S. Trouble is coming: Signaling pathways that regulate general stress responses in bacteria. J. Biol. Chem. 2019, 294, 11685-11700. [CrossRef] [PubMed]

4. Starosta, A.L.; Lassak, J.; Jung, K.; Wilson, D.N. The bacterial translation stress response. FEMS Microbiol. Rev. 2014, 38, 1172-1201. [CrossRef]

5. Moll, I.; Engelberg-Kulka, H. Selective translation during stress in Escherichia coli. Trends Biochem. Sci. 2012, 37, 493-498. [CrossRef] [PubMed]

6. He, C.-G.; Gualerzi, C.O. The Ribosome as a Switchboard for Bacterial Stress Response. Front. Microbiol. 2020, 11, 619038. [CrossRef]

7. Polikanov, Y.S.; Blaha, G.M.; Steitz, T.A. How hibernation factors RMF, HPF, and YfiA turn off protein synthesis. Science 2012, 336, 915-918. [CrossRef] [PubMed]

8. Yoshida, H.; Ueta, M.; Maki, Y.; Sakai, A.; Wada, A. Activities of Escherichia coli ribosomes in IF3 and RMF change to prepare 100S ribosome formation on entering the stationary growth phase. Genes Cells Devoted Mol. Cell. Mech. 2009, 14, 271-280. [CrossRef] [PubMed] 
9. Bürk, J.; Weiche, B.; Wenk, M.; Boy, D.; Nestel, S.; Heimrich, B.; Koch, H.G. Depletion of the signal recognition particle receptor inactivates ribosomes in Escherichia coli. J. Bacteriol. 2009, 191, 7017-7026. [CrossRef] [PubMed]

10. Potrykus, K.; Cashel, M. Growth at best and worst of times. Nat. Microbiol. 2018, 3, 862-863. [CrossRef]

11. Irving, S.E.; Choudhury, N.R.; Corrigan, R.M. The stringent response and physiological roles of (pp)pGpp in bacteria. Nat. Rev. Microbiol. 2021, 19, 256-271. [CrossRef] [PubMed]

12. Steinchen, W.; Zegarra, V.; Bange, G. (p)ppGpp: Magic Modulators of Bacterial Physiology and Metabolism. Front. Microbiol. 2020, 11, 2072. [CrossRef]

13. Haas, T.M.; Qiu, D.; Häner, M.; Angebauer, L.; Ripp, A.; Singh, J.; Koch, H.G.; Jessen-Trefzer, C.; Jessen, H.J. Four Phosphates at One Blow: Access to Pentaphosphorylated Magic Spot Nucleotides and Their Analysis by Capillary Electrophoresis. J. Org. Chem. 2020, 85, 14496-14506. [CrossRef]

14. Trösch, R.; Willmund, F. The conserved theme of ribosome hibernation: From bacteria to chloroplasts of plants. Biol. Chem. 2019, 400, 879-893. [CrossRef] [PubMed]

15. Boniecka, J.; Prusińska, J.; Dabrowska, G.B.; Goc, A. Within and beyond the stringent response-RSH and (p)ppGpp in plants. Planta 2017, 246, 817-842. [CrossRef] [PubMed]

16. Balasingam, N.; Brandon, H.E.; Ross, J.A.; Wieden, H.J.; Thakor, N. Cellular roles of the human Obg-like ATPase 1 (hOLA1) and its YchF homologs. Biochem. Cell Biol. 2020, 98, 1-11. [CrossRef] [PubMed]

17. Verstraeten, N.; Fauvert, M.; Versees, W.; Michiels, J. The universally conserved prokaryotic GTPases. Microbiol. Mol. Biol. Rev. 2011, 75, 507-542. [CrossRef]

18. Rosler, K.S.; Mercier, E.; Andrews, I.C.; Wieden, H.J. Histidine 114 Is Critical for ATP Hydrolysis by the Universally Conserved ATPase YchF. J. Biol. Chem. 2015, 290, 18650-18661. [CrossRef]

19. Koller-Eichhorn, R.; Marquardt, T.; Gail, R.; Wittinghofer, A.; Kostrewa, D.; Kutay, U.; Kambach, C. Human OLA1 defines an ATPase subfamily in the Obg family of GTP-binding proteins. J. Biol. Chem. 2007, 282, 19928-19937. [CrossRef]

20. Wenk, M.; Ba, Q.; Erichsen, V.; MacInnes, K.; Wiese, H.; Warscheid, B.; Koch, H.G. A universally conserved ATPase regulates the oxidative stress response in Escherichia coli. J. Biol. Chem. 2012, 287, 43585-43598. [CrossRef]

21. Zhang, J.; Rubio, V.; Lieberman, M.W.; Shi, Z.Z. OLA1, an Obg-like ATPase, suppresses antioxidant response via nontranscriptional mechanisms. Proc. Natl. Acad. Sci. USA 2009, 106, 15356-15361. [CrossRef]

22. Cheung, M.Y.; Li, M.W.; Yung, Y.L.; Wen, C.Q.; Lam, H.M. The unconventional P-loop NTPase OsYchF1 and its regulator OsGAP1 play opposite roles in salinity stress tolerance. Plant Cell Environ. 2013, 36, 2008-2020. [CrossRef]

23. Grosjean, H.; Breton, M.; Sirand-Pugnet, P.; Tardy, F.; Thiaucourt, F.; Citti, C.; Barré, A.; Yoshizawa, S.; Fourmy, D.; de Crécy-Lagard, V.; et al. Predicting the minimal translation apparatus: Lessons from the reductive evolution of mollicutes. PLoS Genet. 2014, 10, e1004363. [CrossRef] [PubMed]

24. Brown, E.D. Conserved P-loop GTPases of unknown function in bacteria: An emerging and vital ensemble in bacterial physiology Biochem. Cell Biol. 2005, 83, 738-746. [CrossRef] [PubMed]

25. Macek, B.; Gnad, F.; Soufi, B.; Kumar, C.; Olsen, J.V.; Mijakovic, I.; Mann, M. Phosphoproteome analysis of E. coli reveals evolutionary conservation of bacterial Ser/Thr/Tyr phosphorylation. Mol. Cell. Proteom. MCP 2008, 7, 299-307. [CrossRef]

26. Hannemann, L.; Suppanz, I.; Ba, Q.; MacInnes, K.; Drepper, F.; Warscheid, B.; Koch, H.G. Redox Activation of the Universally Conserved ATPase YchF by Thioredoxin 1. Antioxid. Redox Signal. 2016, 24, 141-156. [CrossRef] [PubMed]

27. Teplyakov, A.; Obmolova, G.; Chu, S.Y.; Toedt, J.; Eisenstein, E.; Howard, A.J.; Gilliland, G.L. Crystal structure of the YchF protein reveals binding sites for GTP and nucleic acid. J. Bacteriol. 2003, 185, 4031-4037. [CrossRef]

28. Feng, B.; Mandava, C.S.; Guo, Q.; Wang, J.; Cao, W.; Li, N.; Zhang, Y.; Zhang, Y.; Wang, Z.; Wu, J.; et al. Structural and functional insights into the mode of action of a universally conserved Obg GTPase. PLoS Biol. 2014, 12, e1001866. [CrossRef]

29. Rubio Gomez, M.A.; Ibba, M. Aminoacyl-tRNA synthetases. RNA 2020, 26, 910-936. [CrossRef]

30. Iyer, L.M.; Burroughs, A.M.; Aravind, L. The prokaryotic antecedents of the ubiquitin-signaling system and the early evolution of ubiquitin-like beta-grasp domains. Genome Biol. 2006, 7, R60. [CrossRef]

31. Pohl, C.; Dikic, I. Cellular quality control by the ubiquitin-proteasome system and autophagy. Science 2019, 366, 818-822. [CrossRef] [PubMed]

32. Martín-Villanueva, S.; Gutiérrez, G.; Kressler, D.; de la Cruz, J. Ubiquitin and Ubiquitin-Like Proteins and Domains in Ribosome Production and Function: Chance or Necessity? Int. J. Mol. Sci. 2021, 22, 4359. [CrossRef]

33. Kint, C.; Verstraeten, N.; Hofkens, J.; Fauvart, M.; Michiels, J. Bacterial Obg proteins: GTPases at the nexus of protein and DNA synthesis. Crit. Rev. Microbiol. 2014, 40, 207-224. [CrossRef]

34. Cruz-Vera, L.R.; Galindo, J.M.; Guarneros, G. Transcriptional analysis of the gene encoding peptidyl-tRNA hydrolase in Escherichia coli. Microbiology 2002, 148, 3457-3466. [CrossRef] [PubMed]

35. Das, G.; Varshney, U. Peptidyl-tRNA hydrolase and its critical role in protein biosynthesis. Microbiology 2006, 152, $2191-2195$. [CrossRef] [PubMed]

36. Becker, M.; Gzyl, K.E.; Altamirano, A.M.; Vuong, A.; Urban, K.; Wieden, H.J. The 70S ribosome modulates the ATPase activity of Escherichia coli YchF. RNA Biol. 2012, 9, 1288-1301. [CrossRef] [PubMed]

37. Tomar, S.K.; Kumar, P.; Prakash, B. Deciphering the catalytic machinery in a universally conserved ribosome binding ATPase YchF. Biochem. Biophys. Res. Commun. 2011, 408, 459-464. [CrossRef] 
38. Gradia, D.F.; Rau, K.; Umaki, A.C.; de Souza, F.S.; Probst, C.M.; Correa, A.; Holetz, F.B.; Avila, A.R.; Krieger, M.A.; Goldenberg, S.; et al. Characterization of a novel Obg-like ATPase in the protozoan Trypanosoma cruzi. Int. J. Parasitol. 2009, 39, 49-58. [CrossRef] [PubMed]

39. Chen, H.; Song, R.; Wang, G.; Ding, Z.; Yang, C.; Zhang, J.; Zeng, Z.; Rubio, V.; Wang, L.; Zu, N.; et al. OLA1 regulates protein synthesis and integrated stress response by inhibiting eIF2 ternary complex formation. Sci. Rep. 2015, 5, 13241. [CrossRef]

40. Olinares, P.D.; Ponnala, L.; van Wijk, K.J. Megadalton complexes in the chloroplast stroma of Arabidopsis thaliana characterized by size exclusion chromatography, mass spectrometry, and hierarchical clustering. Mol. Cell. Proteom. MCP 2010, 9, 1594-1615 [CrossRef]

41. Dannenmaier, S.; Desroches Altamirano, C.; Schüler, L.; Zhang, Y.; Hummel, J.; Milanov, M.; Oeljeklaus, S.; Koch, H.G.; Rospert, S.; Alberti, S.; et al. Quantitative proteomics identifies the universally conserved ATPase Ola1p as a positive regulator of heat shock response in Saccharomyces cerevisiae. J. Biol. Chem. 2021, 297, 101050. [CrossRef] [PubMed]

42. Landwehr, V.; Milanov, M.; Angebauer, L.; Hong, J.; Jüngert, G.; Hiersemenzel, A.; Siebler, A.; Schmit, F.; Öztürk, Y.; Dannenmaier, S.; et al. The Universally Conserved ATPase YchF Regulates Translation of Leaderless mRNA in Response to Stress Conditions. Front. Mol. Biosci. 2021, 8, 643696. [CrossRef]

43. Gibbs, M.R.; Moon, K.M.; Warner, B.R.; Chen, M.; Bundschuh, R.; Foster, L.J.; Fredrick, K. Functional Analysis of BipA in E. coli Reveals the Natural Plasticity of 50S Subunit Assembly. J. Mol. Biol. 2020, 432, 5259-5272. [CrossRef] [PubMed]

44. James, N.R.; Brown, A.; Gordiyenko, Y.; Ramakrishnan, V. Translational termination without a stop codon. Science 2016, 354, 1437-1440. [CrossRef]

45. Samanfar, B.; Tan le, H.; Shostak, K.; Chalabian, F.; Wu, Z.; Alamgir, M.; Sunba, N.; Burnside, D.; Omidi, K.; Hooshyar, M.; et al. A global investigation of gene deletion strains that affect premature stop codon bypass in yeast, Saccharomyces cerevisiae. Mol. Biosyst. 2014, 10, 916-924. [CrossRef] [PubMed]

46. Cheung, M.Y.; Xue, Y.; Zhou, L.; Li, M.W.; Sun, S.S.; Lam, H.M. An ancient P-loop GTPase in rice is regulated by a higher plant-specific regulatory protein. J. Biol. Chem. 2010, 285, 37359-37369. [CrossRef]

47. Robledo, S.; Idol, R.A.; Crimmins, D.L.; Ladenson, J.H.; Mason, P.J.; Bessler, M. The role of human ribosomal proteins in the maturation of rRNA and ribosome production. RNA 2008, 14, 1918-1929. [CrossRef] [PubMed]

48. Mohler, K.; Ibba, M. Translational fidelity and mistranslation in the cellular response to stress. Nat. Microbiol. 2017, 2, 17117. [CrossRef] [PubMed]

49. Denks, K.; Sliwinski, N.; Erichsen, V.; Borodkina, B.; Origi, A.; Koch, H.G. The signal recognition particle contacts uL23 and scans substrate translation inside the ribosomal tunnel. Nat. Microbiol. 2017, 2, 16265. [CrossRef]

50. Kudva, R.; Denks, K.; Kuhn, P.; Vogt, A.; Muller, M.; Koch, H.G. Protein translocation across the inner membrane of Gram-negative bacteria: The Sec and Tat dependent protein transport pathways. Res. Microbiol. 2013, 164, 505-534. [CrossRef] [PubMed]

51. Danese, I.; Haine, V.; Delrue, R.M.; Tibor, A.; Lestrate, P.; Stevaux, O.; Mertens, P.; Paquet, J.Y.; Godfroid, J.; de Bolle, X.; et al. The Ton system, an $\mathrm{ABC}$ transporter, and a universally conserved GTPase are involved in iron utilization by Brucella melitensis $16 \mathrm{M}$. Infect. Immun. 2004, 72, 5783-5790. [CrossRef] [PubMed]

52. Sternon, J.F.; Godessart, P.; Gonçalves de Freitas, R.; van der Henst, M.; Poncin, K.; Francis, N.; Willemart, K.; Christen, M.; Christen, B.; Letesson, J.J.; et al. Transposon Sequencing of Brucella abortus Uncovers Essential Genes for Growth In Vitro and Inside Macrophages. Infect. Immun. 2018, 86, e00312-18. [CrossRef]

53. Fernebro, J.; Blomberg, C.; Morfeldt, E.; Wolf-Watz, H.; Normark, S.; Normark, B.H. The influence of in vitro fitness defects on pneumococcal ability to colonize and to cause invasive disease. BMC Microbiol. 2008, 8, 65. [CrossRef] [PubMed]

54. Chen, Y.C.; Chung, Y.T. A conserved GTPase YchF of Vibrio vulnificus is involved in macrophage cytotoxicity, iron acquisition, and mouse virulence. Int. J. Med. Microbiol. IJMM 2011, 301, 469-474. [CrossRef]

55. Guerrero, C.; Tagwerker, C.; Kaiser, P.; Huang, L. An integrated mass spectrometry-based proteomic approach: Quantitative analysis of tandem affinity-purified in vivo cross-linked protein complexes (QTAX) to decipher the $26 \mathrm{~S}$ proteasome-interacting network. Mol. Cell. Proteom. MCP 2006, 5, 366-378. [CrossRef] [PubMed]

56. Cheung, M.Y.; Li, X.; Miao, R.; Fong, Y.H.; Li, K.P.; Yung, Y.L.; Yu, M.H.; Wong, K.B.; Chen, Z.; Lam, H.M. ATP binding by the P-loop NTPase OsYchF1 (an unconventional G protein) contributes to biotic but not abiotic stress responses. Proc. Natl. Acad. Sci. USA 2016, 113, 2648-2653. [CrossRef]

57. Bai, L.; Yu, Z.; Zhang, J.; Yuan, S.; Liao, C.; Jeyabal, P.V.; Rubio, V.; Chen, H.; Li, Y.; Shi, Z.Z. OLA1 contributes to epithelialmesenchymal transition in lung cancer by modulating the GSK3 $\beta$ /snail/E-cadherin signaling. Oncotarget 2016, 7, 10402-10413. [CrossRef]

58. Ding, Z.; Liu, Y.; Rubio, V.; He, J.; Minze, L.J.; Shi, Z.Z. Ola1, a translational regulator of p21, maintains optimal cell proliferation necessary for developmental progression. Mol. Cell. Biol. 2016, 36, 2568-2582. [CrossRef] [PubMed]

59. Schultz, A.; Olorundami, O.A.; Teng, R.J.; Jarzembowski, J.; Shi, Z.Z.; Kumar, S.N.; Pritchard, K., Jr.; Konduri, G.G.; Afolayan, A.J. Decreased OLA1 (Obg-Like ATPase-1) Expression Drives Ubiquitin-Proteasome Pathways to Downregulate Mitochondrial SOD2 (Superoxide Dismutase) in Persistent Pulmonary Hypertension of the Newborn. Hypertension 2019, 74, 957-966. [CrossRef] [PubMed]

60. Matsuzawa, A.; Kanno, S.; Nakayama, M.; Mochiduki, H.; Wei, L.; Shimaoka, T.; Furukawa, Y.; Kato, K.; Shibata, S.; Yasui, A.; et al. The BRCA1/BARD1-interacting protein OLA1 functions in centrosome regulation. Mol. Cell 2014, 53, 101-114. [CrossRef] [PubMed] 
61. Sun, H.; Luo, X.; Montalbano, J.; Jin, W.; Shi, J.; Sheikh, M.S.; Huang, Y. DOC45, a novel DNA damage-regulated nucleocytoplasmic ATPase that is overexpressed in multiple human malignancies. Mol. Cancer Res. MCR 2010, 8, 57-66. [CrossRef]

62. Zhang, J.W.; Rubio, V.; Zheng, S.; Shi, Z.Z. Knockdown of OLA1, a regulator of oxidative stress response, inhibits motility and invasion of breast cancer cells. J. Zhejiang Univ. Sci. B 2009, 10, 796-804. [CrossRef] [PubMed]

63. Zhang, Y.; Gross, C.A. Cold Shock Response in Bacteria. Annu. Rev. Genet. 2021, 55, 377-400. [CrossRef] [PubMed]

64. Sawasato, K.; Suzuki, S.; Nishiyama, K.I. Increased expression of the bacterial glycolipid MPIase is required for efficient protein translocation across membranes in cold conditions. J. Biol. Chem. 2019, 294, 8403-8411. [CrossRef] [PubMed]

65. Storz, G.; Tartaglia, L.A.; Ames, B.N. Transcriptional regulator of oxidative stress-inducible genes: Direct activation by oxidation. Science 1990, 248, 189-194. [CrossRef]

66. Imlay, J.A. The molecular mechanisms and physiological consequences of oxidative stress: Lessons from a model bacterium. Nat. Rev. Microbiol. 2013, 11, 443-454. [CrossRef]

67. Sauerbrei, B.; Arends, J.; Schünemann, D.; Narberhaus, F. Lon Protease Removes Excess Signal Recognition Particle Protein in Escherichia coli. J. Bacteriol. 2020, 202, e00161-20. [CrossRef]

68. Mahmoud, S.A.; Chien, P. Regulated Proteolysis in Bacteria. Annu. Rev. Biochem. 2018, 87, 677-696. [CrossRef]

69. Mao, R.F.; Rubio, V.; Chen, H.; Bai, L.; Mansour, O.C.; Shi, Z.Z. OLA1 protects cells in heat shock by stabilizing HSP70. Cell Death Dis. 2013, 4, e491. [CrossRef]

70. Sawada, N.; Ueno, S.; Takeda, K. Regulation of inorganic polyphosphate is required for proper vacuolar proteolysis in fission yeast. J. Biol. Chem. 2021, 297, 100891. [CrossRef]

71. Xie, L.; Jakob, U. Inorganic polyphosphate, a multifunctional polyanionic protein scaffold. J. Biol. Chem. 2019, 294, 2180-2190. [CrossRef]

72. Wallace, E.W.; Kear-Scott, J.L.; Pilipenko, E.V.; Schwartz, M.H.; Laskowski, P.R.; Rojek, A.E.; Katanski, C.D.; Riback, J.A.; Dion, M.F.; Franks, A.M.; et al. Reversible, Specific, Active Aggregates of Endogenous Proteins Assemble upon Heat Stress. Cell 2015, 162, 1286-1298. [CrossRef] [PubMed]

73. Xu, D.; Song, R.; Wang, G.; Jeyabal, P.V.; Weiskoff, A.M.; Ding, K.; Shi, Z.Z. Obg-like ATPase 1 regulates global protein serine/threonine phosphorylation in cancer cells by suppressing the GSK3beta-inhibitor 2-PP1 positive feedback loop. Oncotarget 2016, 7, 3427-3439. [CrossRef]

74. Jeyabal, P.V.; Rubio, V.; Chen, H.; Zhang, J.; Shi, Z.Z. Regulation of cell-matrix adhesion by OLA1, the Obg-like ATPase 1. Biochem. Biophys. Res. Commun. 2014, 444, 568-574. [CrossRef]

75. Chuang, H.H.; Zhen, Y.Y.; Tsai, Y.C.; Chuang, C.H.; Huang, M.S.; Hsiao, M.; Yang, C.J. Targeting Pin1 for Modulation of Cell Motility and Cancer Therapy. Biomedicines 2021, 9, 359. [CrossRef] [PubMed]

76. Gomez, V.; Hergovich, A. OLA1 in centrosome biology alongside the BRCA1/BARD1 complex: Looking beyond centrosomes. Mol. Cell 2014, 53, 3-5. [CrossRef] [PubMed]

77. Yoshino, Y.; Fang, Z.; Qi, H.; Kobayashi, A.; Chiba, N. Dysregulation of the centrosome induced by BRCA1 deficiency contributes to tissue-specific carcinogenesis. Cancer Sci. 2021, 112, 1679-1687. [CrossRef] [PubMed]

78. Yoshino, Y.; Qi, H.; Fujita, H.; Shirota, M.; Abe, S.; Komiyama, Y.; Shindo, K.; Nakayama, M.; Matsuzawa, A.; Kobayashi, A.; et al BRCA1-Interacting Protein OLA1 Requires Interaction with BARD1 to Regulate Centrosome Number. Mol. Cancer Res. MCR 2018, 16, 1499-1511. [CrossRef] [PubMed]

79. Yoshino, Y.; Qi, H.; Kanazawa, R.; Sugamata, M.; Suzuki, K.; Kobayashi, A.; Shindo, K.; Matsuzawa, A.; Shibata, S.; Endo, S.; et al. RACK1 regulates centriole duplication by controlling localization of BRCA1 to the centrosome in mammary tissue-derived cells. Oncogene 2019, 38, 3077-3092. [CrossRef]

80. Witus, S.R.; Stewart, M.D.; Klevit, R.E. The BRCA1/BARD1 ubiquitin ligase and its substrates. Biochem. J. 2021, 478, 3467-3483. [CrossRef]

81. Korovila, I.; Hugo, M.; Castro, J.P.; Weber, D.; Höhn, A.; Grune, T.; Jung, T. Proteostasis, oxidative stress and aging. Redox Biol. 2017, 13, 550-567. [CrossRef]

82. Höhfeld, J.; Benzing, T.; Bloch, W.; Fürst, D.O.; Gehlert, S.; Hesse, M.; Hoffmann, B.; Hoppe, T.; Huesgen, P.F.; Köhn, M.; et al. Maintaining proteostasis under mechanical stress. EMBO Rep. 2021, 22, e52507. [CrossRef]

83. Milón, P.; Rodnina, M.V. Kinetic control of translation initiation in bacteria. Crit. Rev. Biochem. Mol. Biol. 2012, 47, 334-348. [CrossRef] [PubMed]

84. Rodnina, M.V. Translation in Prokaryotes. Cold Spring Harb. Perspect. Biol. 2018, 10, a032664. [CrossRef]

85. Milón, P.; Maracci, C.; Filonava, L.; Gualerzi, C.O.; Rodnina, M.V. Real-time assembly landscape of bacterial $30 S$ translation initiation complex. Nat. Struct. Mol. Biol. 2012, 19, 609-615. [CrossRef]

86. Sriram, A.; Bohlen, J.; Teleman, A.A. Translation acrobatics: How cancer cells exploit alternate modes of translational initiation. EMBO Rep. 2018, 19, e45947. [CrossRef]

87. Myasnikov, A.G.; Simonetti, A.; Marzi, S.; Klaholz, B.P. Structure-function insights into prokaryotic and eukaryotic translation initiation. Curr. Opin. Struct. Biol. 2009, 19, 300-309. [CrossRef] [PubMed]

88. Girardin, S.E.; Cuziol, C.; Philpott, D.J.; Arnoult, D. The eIF2 $\alpha$ kinase HRI in innate immunity, proteostasis, and mitochondrial stress. FEBS J. 2021, 288, 3094-3107. [CrossRef] [PubMed]

89. Pakos-Zebrucka, K.; Koryga, I.; Mnich, K.; Ljujic, M.; Samali, A.; Gorman, N.A. The integrated stress response. EMBO Rep. 2016, 17, 1374-1395. [CrossRef] 
90. Guo, X.; Aviles, G.; Liu, Y.; Tian, R.; Unger, B.A.; Lin, Y.T.; Wiita, A.P.; Xu, K.; Correia, M.A.; Kampmann, M. Mitochondrial stress is relayed to the cytosol by an OMA1-DELE1-HRI pathway. Nature 2020, 579, 427-432. [CrossRef]

91. Fessler, E.; Eckl, E.M.; Schmitt, S.; Mancilla, I.A.; Meyer-Bender, M.F.; Hanf, M.; Philippou-Massier, J.; Krebs, S.; Zischka, H.; Jae, L.T. A pathway coordinated by DELE1 relays mitochondrial stress to the cytosol. Nature 2020, 579, 433-437. [CrossRef] [PubMed]

92. Gomez, M.; Germain, D. Cross talk between SOD1 and the mitochondrial UPR in cancer and neurodegeneration. Mol. Cell. Neurosci. 2019, 98, 12-18. [CrossRef] [PubMed]

93. Pitale, P.M.; Gorbatyuk, O.; Gorbatyuk, M. Neurodegeneration: Keeping ATF4 on a Tight Leash. Front. Cell. Neurosci. 2017, 11, 410. [CrossRef] [PubMed]

94. D'Osualdo, A.; Anania, V.G.; Yu, K.; Lill, J.R.; Kaufman, R.J.; Matsuzawa, S.; Reed, J.C. Transcription Factor ATF4 Induces NLRP1 Inflammasome Expression during Endoplasmic Reticulum Stress. PLoS ONE 2015, 10, e0130635. [CrossRef]

95. Siu, F.; Bain, P.J.; LeBlanc-Chaffin, R.; Chen, H.; Kilberg, M.S. ATF4 is a mediator of the nutrient-sensing response pathway that activates the human asparagine synthetase gene. J. Biol. Chem. 2002, 277, 24120-24127. [CrossRef]

96. Wortel, I.M.N.; van der Meer, L.T.; Kilberg, M.S.; van Leeuwen, F.N. Surviving Stress: Modulation of ATF4-Mediated Stress Responses in Normal and Malignant Cells. Trends Endocrinol. Metab. TEM 2017, 28, 794-806. [CrossRef]

97. Sarnow, P. Viral internal ribosome entry site elements: Novel ribosome-RNA complexes and roles in viral pathogenesis. J. Virol. 2003, 77, 2801-2806. [CrossRef]

98. Spriggs, K.A.; Stoneley, M.; Bushell, M.; Willis, A.E. Re-programming of translation following cell stress allows IRES-mediated translation to predominate. Biol. Cell 2008, 100, 27-38. [CrossRef]

99. Gualerzi, C.O.; Pon, C.L. Initiation of mRNA translation in bacteria: Structural and dynamic aspects. Cell. Mol. Life Sci. CMLS 2015, 72, 4341-4367. [CrossRef]

100. Milon, P.; Konevega, A.L.; Gualerzi, C.O.; Rodnina, M.V. Kinetic checkpoint at a late step in translation initiation. Mol. Cell 2008, 30, 712-720. [CrossRef]

101. Beck, H.J.; Moll, I. Leaderless mRNAs in the Spotlight: Ancient but Not Outdated! Microbiol. Spectr. 2018, 6. [CrossRef] [PubMed]

102. Nakagawa, S.; Niimura, Y.; Gojobori, T. Comparative genomic analysis of translation initiation mechanisms for genes lacking the Shine-Dalgarno sequence in prokaryotes. Nucleic Acids Res. 2017, 45, 3922-3931. [CrossRef] [PubMed]

103. De Groot, A.; Roche, D.; Fernandez, B.; Ludanyi, M.; Cruveiller, S.; Pignol, D.; Vallenet, D.; Armengaud, J.; Blanchard, L. RNA sequencing and proteogenomics reveal the importance of leaderless mRNAs in the radiation-tolerant bacterium Deinococcus deserti. Genome Biol. Evol. 2014, 6, 932-948. [CrossRef]

104. Ignatov, D.; Malakho, S.; Majorov, K.; Skvortsov, T.; Apt, A.; Azhikina, T. RNA-Seq analysis of Mycobacterium avium non-coding transcriptome. PLoS ONE 2013, 8, e74209. [CrossRef]

105. Grabowska, A.D.; Andreu, N.; Cortes, T. Translation of a Leaderless Reporter Is Robust during Exponential Growth and Well Sustained during Stress Conditions in Mycobacterium tuberculosis. Front. Microbiol. 2021, 12, 746320. [CrossRef] [PubMed]

106. Shell, S.S.; Wang, J.; Lapierre, P.; Mir, M.; Chase, M.R.; Pyle, M.M.; Gawande, R.; Ahmad, R.; Sarracino, D.A.; Ioerger, T.R.; et al. Leaderless Transcripts and Small Proteins Are Common Features of the Mycobacterial Translational Landscape. PLoS Genet. 2015, 11, e1005641. [CrossRef] [PubMed]

107. Babski, J.; Haas, K.A.; Näther-Schindler, D.; Pfeiffer, F.; Förstner, K.U.; Hammelmann, M.; Hilker, R.; Becker, A.; Sharma, C.M.; Marchfelder, A.; et al. Genome-wide identification of transcriptional start sites in the haloarchaeon Haloferax volcanii based on differential RNA-Seq (dRNA-Seq). BMC Genom. 2016, 17, 629. [CrossRef]

108. Gelsinger, D.R.; Dallon, E.; Reddy, R.; Mohammad, F.; Buskirk, A.R.; DiRuggiero, J. Ribosome profiling in archaea reveals leaderless translation, novel translational initiation sites, and ribosome pausing at single codon resolution. Nucleic Acids Res. 2020, 48, 5201-5216. [CrossRef]

109. Schmitt, E.; Coureux, P.D.; Kazan, R.; Bourgeois, G.; Lazennec-Schurdevin, C.; Mechulam, Y. Recent Advances in Archaeal Translation Initiation. Front. Microbiol. 2020, 11, 584152. [CrossRef]

110. Romero, D.A.; Hasan, A.H.; Lin, Y.F.; Kime, L.; Ruiz-Larrabeiti, O.; Urem, M.; Bucca, G.; Mamanova, L.; Laing, E.E.; van Wezel, G.P.; et al. A comparison of key aspects of gene regulation in Streptomyces coelicolor and Escherichia coli using nucleotide-resolution transcription maps produced in parallel by global and differential RNA sequencing. Mol. Microbiol. 2014, 94, 963-987. [CrossRef]

111. Vesper, O.; Amitai, S.; Belitsky, M.; Byrgazov, K.; Kaberdina, A.C.; Engelberg-Kulka, H.; Moll, I. Selective translation of leaderless mRNAs by specialized ribosomes generated by MazF in Escherichia coli. Cell 2011, 147, 147-157. [CrossRef]

112. Sauert, M.; Wolfinger, M.T.; Vesper, O.; Müller, C.; Byrgazov, K.; Moll, I. The MazF-regulon: A toolbox for the post-transcriptional stress response in Escherichia coli. Nucleic Acids Res. 2016, 44, 6660-6675. [CrossRef] [PubMed]

113. Amitai, S.; Kolodkin-Gal, I.; Hananya-Meltabashi, M.; Sacher, A.; Engelberg-Kulka, H. Escherichia coli MazF leads to the simultaneous selective synthesis of both "death proteins" and "survival proteins". PLoS Genet. 2009, 5, e1000390. [CrossRef] [PubMed]

114. Nigam, A.; Ziv, T.; Oron-Gottesman, A.; Engelberg-Kulka, H. Stress-Induced MazF-Mediated Proteins in Escherichia coli. mBio 2019, 10, 1-9. [CrossRef]

115. Cook, G.M.; Robson, J.R.; Frampton, R.A.; McKenzie, J.; Przybilski, R.; Fineran, P.C.; Arcus, V.L. Ribonucleases in bacterial toxin-antitoxin systems. Biochim. Biophys. Acta 2013, 1829, 523-531. [CrossRef] [PubMed] 
116. Culviner, P.H.; Laub, M.T. Global Analysis of the E. coli Toxin MazF Reveals Widespread Cleavage of mRNA and the Inhibition of rRNA Maturation and Ribosome Biogenesis. Mol. Cell 2018, 70, 868-880.e810. [CrossRef]

117. Mets, T.; Lippus, M.; Schryer, D.; Liiv, A.; Kasari, V.; Paier, A.; Maivali, U.; Remme, J.; Tenson, T.; Kaldalu, N. Toxins MazF and MqsR cleave Escherichia coli rRNA precursors at multiple sites. RNA Biol. 2017, 14, 124-135. [CrossRef]

118. Byrgazov, K.; Vesper, O.; Moll, I. Ribosome heterogeneity: Another level of complexity in bacterial translation regulation. Curr. Opin. Microbiol. 2013, 16, 133-139. [CrossRef]

119. Nakagawa, S.; Niimura, Y.; Miura, K.; Gojobori, T. Dynamic evolution of translation initiation mechanisms in prokaryotes. Proc. Natl. Acad. Sci. USA 2010, 107, 6382-6387. [CrossRef]

120. Saito, K.; Green, R.; Buskirk, A.R. Translational initiation in E. coli occurs at the correct sites genome-wide in the absence of mRNA-rRNA base-pairing. Elife 2020, 9, e55002. [CrossRef]

121. Hockenberry, A.J.; Stern, A.J.; Amaral, L.A.N.; Jewett, M.C. Diversity of Translation Initiation Mechanisms across Bacterial Species Is Driven by Environmental Conditions and Growth Demands. Mol. Biol. Evol. 2018, 35, 582-592. [CrossRef]

122. O'Donnell, S.M.; Janssen, G.R. Leaderless mRNAs bind $70 S$ ribosomes more strongly than 30 S ribosomal subunits in Escherichia coli. J. Bacteriol. 2002, 184, 6730-6733. [CrossRef]

123. Udagawa, T.; Shimizu, Y.; Ueda, T. Evidence for the translation initiation of leaderless mRNAs by the intact $70 \mathrm{~S}$ ribosome without its dissociation into subunits in eubacteria. J. Biol. Chem. 2004, 279, 8539-8546. [CrossRef] [PubMed]

124. Moll, I.; Hirokawa, G.; Kiel, M.C.; Kaji, A.; Bläsi, U. Translation initiation with 70S ribosomes: An alternative pathway for leaderless mRNAs. Nucleic Acids Res. 2004, 32, 3354-3363. [CrossRef] [PubMed]

125. Goyal, A.; Belardinelli, R.; Rodnina, M.V. Non-canonical Binding Site for Bacterial Initiation Factor 3 on the Large Ribosomal Subunit. Cell Rep. 2017, 20, 3113-3122. [CrossRef] [PubMed]

126. Koripella, R.K.; Sharma, M.R.; Haque, M.E.; Risteff, P.; Spremulli, L.L.; Agrawal, R.K. Structure of Human Mitochondrial Translation Initiation Factor 3 Bound to the Small Ribosomal Subunit. iScience 2019, 12, 76-86. [CrossRef] [PubMed]

127. Giuliodori, A.M.; Brandi, A.; Giangrossi, M.; Gualerzi, C.O.; Pon, C.L. Cold-stress-induced de novo expression of infC and role of IF3 in cold-shock translational bias. RNA 2007, 13, 1355-1365. [CrossRef]

128. Leiva, L.E.; Orellana, O.; Ibba, M.; Katz, A. Enhanced translation of leaderless mRNAs under oxidative stress in Escherichia coli. bioRxiv 2021. [CrossRef]

129. Morgenstern, M.; Stiller, S.B.; Lübbert, P.; Peikert, C.D.; Dannenmaier, S.; Drepper, F.; Weill, U.; Höß, P.; Feuerstein, R.; Gebert, M.; et al. Definition of a High-Confidence Mitochondrial Proteome at Quantitative Scale. Cell Rep. 2017, 19, $2836-2852$. [CrossRef] [PubMed]

130. Akhova, A.V.; Tkachenko, A.G. ATP/ADP alteration as a sign of the oxidative stress development in Escherichia coli under antibiotic treatment. FEMS Microbiol. Lett. 2014, 353, 69-76. [CrossRef]

131. Bruhn-Olszewska, B.; Molodtsov, V.; Sobala, M.; Dylewski, M.; Murakami, K.S.; Cashel, M.; Potrykus, K. Structure-function comparisons of (p)ppApp vs (p)ppGpp for Escherichia coli RNA polymerase binding sites and for rrnB P1 promoter regulatory responses in vitro. Biochim. Biophys. Acta Gene Regul. Mech. 2018, 1861, 731-742. [CrossRef] [PubMed]

132. Anderson, B.W.; Fung, D.K.; Wang, J.D. Regulatory Themes and Variations by the Stress-Signaling Nucleotide Alarmones (p)ppGpp in Bacteria. Annu. Rev. Genet. 2021, 55, 115-133. [CrossRef] [PubMed]

133. Haghdoost, S.; Sjölander, L.; Czene, S.; Harms-Ringdahl, M. The nucleotide pool is a signficant target for oxidative stress. Free Radic Biol. Med. 2006, 41, 620-626. [CrossRef] [PubMed] 